Para citar este artículo: Pardo Siabato, C. (2019). Cine para los oídos. Un estudio de caso: análisis de la propuesta sonora de la película Babel. Anuario Electrónico de Estudios en Comunicación Social "Disertaciones", 12(2), 197-215. Doi: http://dx.doi.org/10.12804/revistas.urosario.edu.co/disertaciones/a.6419

\title{
CINE PARA LOS OÍDOS. UN ESTUDIO DE CASO: ANÁLISIS DE LA PROPUESTA SONORA DE LA PELÍCULA BABEL
}

\author{
Cinema for the Ears. A Case Study: Analysis of the Sound Design \\ in the Movie Babel
}

\section{Cinema para os ouvidos. Um estudo de caso: análise da proposta sonora do filme Babel}

Camilo Pardo Siabato, Universidad Iberoamericana (México)

cineparalosoidos@gmail.com

\section{RESUMEN}

Este artículo busca mostrar la expresividad del sonido dentro del discurso narrativo de la propuesta sonora de la película Babel (2006) con un análisis basado en la metodología de Michel Chion y un diálogo con los diversos componentes cinematográficos.

Palabras clave: sonido, cine, Babel, Iñárritu. 


\section{DISERTACIONES}

El papel del sonido en la comunicación: contribución, funciones y efectos

ISSN: $1856-9536$

Doi: http://dx.doi.org/10.12804/revistas.urosario.edu.co/disertaciones/a.6419

Volumen 12, Número 2 / Julio-diciembre 2019

Versión PDF para imprimir desde

http://revistas.urosario.edu.co/index.php/disertaciones

\section{ABSTRACT}

This article seeks to show the expressiveness of sound within the narrative discourse of the Babel's sound design with an analysis based on Michel Chion's methodology and a correlations between the elements of cinematography.

Keywords: Sound, film, Babel, Iñárritu.

\section{RESUMO}

Este artigo busca mostrar a expressividade do som dentro do discurso narrativo da proposta sonora da película Babel (2006) com uma análise baseada na metodologia de Michel Chion e um diálogo com os diversos componentes cinematográficos.

Palavras-chave: som, cinema, Babel, Iñárritu.

\section{Una introducción a la investigación sonora}

El cine puede ser entendido como un medio de comunicación audiovisual, donde convergen y se relacionan componentes sonoros y visuales: dos entes que están fusionados intrínsecamente en todos los productos de esta factura. Sin embargo, este diálogo entre lo que perciben los oídos y los ojos se establece antes, incluso, de que pudieran registrarse técnicamente los sonidos y las imágenes, mucho antes del nacimiento del cine. En una revisión histórica, Jullier (2007, p. 19) apunta que todos los espectáculos de imágenes animadas que se conocen en el transcurso de la historia se desarrollaron con acompañamientos sonoros, desde las marionetas indonesias hasta el praxinoscopio (antecesor del espectáculo cinematográfico), siempre hubo música, palabras o sonidos: esto hace que se pueda pensar el entretenimiento como un fenómeno tradicionalmente audiovisual.

No obstante, es importante reconocer que hasta hace muy poco, menos de 150 años, no se tenía la posibilidad de registrar técnicamente el sonido, por ende, de manipularlo, reproducirlo, alterarlo y analizarlo a discreción. En este sentido, el profesor Mauricio Bejarano (2007, p. 15) de la Universidad Nacional de Colombia afirma que, en 1877, se estableció la tecnología para registrar las ondas sonoras con el fonógrafo de Thomas Alva Edison, el primer grabador de sonido. El fonógrafo constaba de un cilindro desplazable con manivela y recubierto con una hoja de estaño, además de una aguja de acero en su centro, una cortada a bisel para grabar y otra redonda para leer. El alcance de esta nueva tecnología fue un parteaguas histórico para la reflexión alrededor del mundo sonoro; el alemán Marcel Meyer (1999) habla de esto:

El mundo, antes de que pudieran examinarse las voces, no existía. Hasta la invención del fonógrafo por

Edison, el mundo de los sonidos solo podía manifestarse exclusivamente en una fugaz presencia, a su lado no 


\section{DISERTACIONES}

ESTUDIOS

El papel del sonido en la comunicación: contribución, funciones y efectos

ISSN: $1856-9536$

Doi: http://dx.doi.org/10.12804/revistas.urosario.edu.co/disertaciones/a.6419

Volumen 12, Número 2 / Julio-diciembre 2019

Versión PDF para imprimir desde

http://revistas.urosario.edu.co/index.php/disertaciones

existía más que una repetición más queda, más difusa ante el oído interno o, aún menos fiable, la confrontación de sonidos irreales en la imaginación. Luego, en 1877, de repente la apertura de una esfera insospechada de la acústica [...] la matización se abrió paso. Desde entonces, cualquier matiz puede servir de referencia para ser comparado arbitrariamente con otro por muy poca diferencia que haya entre ambos (p. 130).

Esta posibilidad tecnológica relativamente reciente propició la investigación moderna de los objetos sonoros y, a partir de ella, se han podido realizar análisis tangibles sobre la naturaleza del sonido, reconocer sus propiedades físicas y la percepción anatómica en los seres humanos, dando como resultado la multiplicación de las posibilidades artísticas y expresivas, tanto en radio como en cine, televisión, música, arte y reflexión sonora.

Por ello, en las últimas décadas, se pueden identificar algunas voces relevantes que han generado investigaciones y conceptos consistentes que ayudan a profundizar el estudio del sonido. Tal es el caso del canadiense Murray Schafer y sus grandes aportaciones, como paisaje sonoro, aculogía y su World Soundscape Project, y, en la actualidad, se pueden encontrar registros de distintas sonoridades del mundo a través de la internet. También se puede contar con el francés Michel Chion, que ha teorizado sobre la interacción entre sonido e imagen, generando una nutrida literatura que coloca en un lugar central el espectro audible con conceptos como audiovisión, acusmaser, vocentrismo, ergoaudición, etc.

Existe también una variada bibliografía sobre el estudio de la música en general, y en particular: respecto a su sinergia con las imágenes en el lenguaje cinematográfico, se pueden encontrar voces relevantes, como es el caso de la escritora Anahid Kassabian y su Hearing Film: Tracking Identifications in Contemporary Hollywood Film Music, quien pone a la música en el centro de la narrativa fílmica; otra voz femenina destacada es la de Carol Vernallis con libros y artículos que buscan articular una teoría de cómo la música, la letra y la imagen se relacionan entre sí en un producto audiovisual, y, por supuesto, los trabajos de Michel Chion y Theodor Adorno respecto a la música y el cine.

Finalmente, es importante profundizar la discusión académica y creativa sobre el papel fundamental que desempeña la banda sonora, entendida como el componente narrativo en el que intervienen todos los elementos audibles en una propuesta cinematográfica (voces, ambientes, música, efectos sonoros, silencio, etc.). En ese sentido, este texto pretende incrementar las reflexiones en torno al papel del sonido en el lenguaje audiovisual, más allá de la música, partiendo del análisis de la propuesta sonora de la película Babel, develando nuevos significados y encontrando otros sentidos basados en la propuesta metodológica presentada por Michel Chion en su libro Audiovisión; de esta manera, se busca aportar nuevos conocimientos que, entre otras cosas, ayuden a elevar la voz de la activa, pero joven, investigación sonora.

\section{¿Por qué Iñárritu y Hernández?}

Al realizar una escucha detallada de algunas de las producciones de González Iñárritu (11'09"01 - September 11, Babel y Naran Ja), se percibe el trabajo esmerado que tienen las propuestas sonoras en cada una de estas producciones. Podría afirmarse que Iñárritu no ha sucumbido al autoritarismo de lo visual o, por lo menos, genera un diálogo más interesante entre lo audible y lo visible que otros cineastas actuales. Posiblemente, la razón de este cuidadoso manejo de lo sonoro se vincula con que sus inicios fueron a través de la radio. "Otra enseñanza importante fue la que me dio mi trabajo en la radio. Ahí aprendí a comunicarme con el público. Es un medio muy generoso, profundamente creativo, en donde, literalmente, el único límite es tu capacidad de imaginación” (Pellicer, 2010). 
La estancia de González Iñárritu en la producción radial fue de cinco años, aproximadamente. En sus programas, entretenía a los oyentes durante tres horas diarias, con música, relato de personajes e historias. Esto fungió como una gran escuela de articulación de ritmo y tono para el futuro director cinematográfico. En este período, surge un producto audiovisual (ver figura 1) que podría sintetizar la estructuración mental entre narrativa y sonido del director.

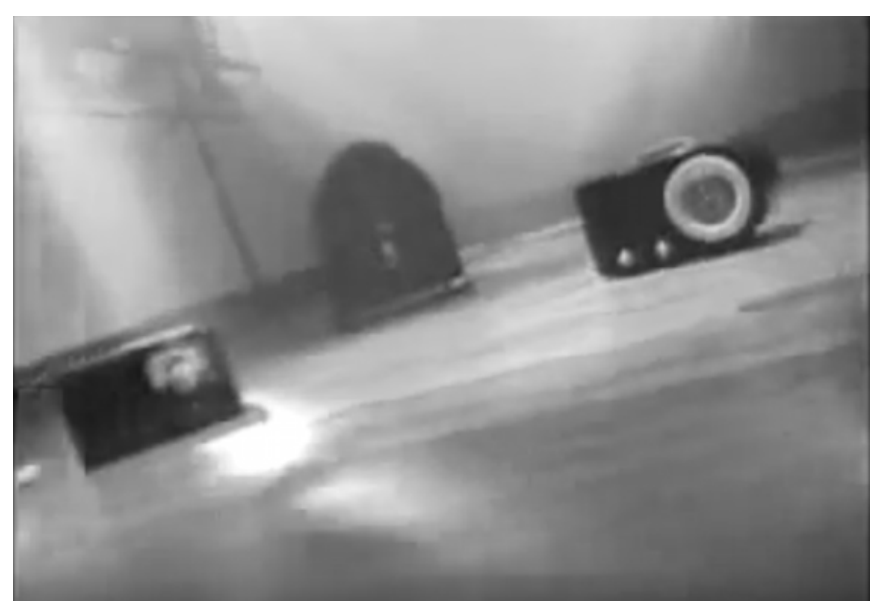

Figura 1. Comercial para televisión

* Cada uno de los tres locutores de un programa radial son representados por un radio ubicado en una sala vacía.

En el comercial, la cámara recorre rápidamente la habitación mientras unos potentes rayos de luz entran por las ventanas iluminando la trayectoria, luego la cámara se detiene frente a un radio antiguo colocado sobre el piso de madera. Enseguida se escucha una voz, con textura de transmisión radial: "¿Qué tal? Yo soy Martín Hernández". Mientras se escucha esta voz, una luz amarilla parpadea sincrónicamente en la pantalla del dial del aparato. Suena un efecto de cambio de canal de televisión y se ve una breve imagen de ruido blanco, la cámara se mueve hacia la derecha para enfocar otro radio antiguo. Ahora se oye una voz femenina, con el mismo efecto sonoro, que dice: "Yo soy Charo Fernández". Y un nuevo corte sonoro y visual. Ahora la cámara reencuadra un tercer aparato. Es un radio más moderno que los anteriores. La cámara hace un recorrido de casi 90 grados sobre él y una voz masculina, reiterando el efecto de sonido de radio, advierte: "Y yo soy Alejandro González Iñárritu, estamos un poco nerviosos, hemos sido descubiertos en televisión, y nosotros hemos sido siempre gente de radio".

Este comercial hace referencia a la estación de radio de los años ochenta, donde trabajaba González Iñárritu, y fue emitido por canales de televisión de la Ciudad de México (muy probablemente con la intención de atraer audiencia a la estación). Sin embargo, la realización de este promocional también puede ser tomado casi como un experimento transmediático, ya que presenta la de intrusión de un medio sonoro (la radio) en un medio que mezcla imágenes y sonidos (la televisión). 


\section{DISERTACIONES}

ESTUDIOS

El papel del sonido en la comunicación: contribución, funciones y efectos

ISSN: $1856-9536$

Doi: http://dx.doi.org/10.12804/revistas.urosario.edu.co/disertaciones/a.6419

Volumen 12, Número 2 / Julio-diciembre 2019

Versión PDF para imprimir desde

http://revistas.urosario.edu.co/index.php/disertaciones

Si bien no pretende ni alcanza a considerarse de lleno como narrativa transmedia (tal como lo propone Scolari), este comercial expone un discurso a través de textos irreverentes, contradictorios y sonoros que hablan, entre otras cosas, sobre la construcción del imaginario que tiene el público de los locutores, de las posibilidades de 'escuchar por televisión' y ‘ver por radio', en suma, pone a dialogar los distintos medios de comunicación.

Este ejemplo manifiesta la preocupación consciente de Iñárritu en la relación entre el diálogo, la tensión, la sinergia, la contraposición, que existe o que potencialmente se puede desarrollar entre los sonidos y las imágenes que conforman un producto audiovisual.

Vale reparar en este punto que, en las aulas del Departamento de Comunicación de la Universidad Iberoamericana, se estableció la amistad (que luego se fortaleció en W Radio) entre Iñárritu y Martín Hernández. Una sinergia de trabajo y reflexión alrededor del universo sonoro que reverberó en la realización conjunta de (hasta ahora) ocho producciones audiovisuales multipremiadas: Amores perros (2000), 11'09'01 - September 11 (2002), 21 gramos (2003), Babel (2006), Biutiful (2010), Naran ja (2012), Birdman (2014) y El renacido (2015). El sonidista Martín Hernández, en una entrevista con Cristina Alemán, en la última versión del Festival de Cine de Morelia, aportó más datos sobre Iñárritu y el sonido:

Alejandro es mucho más un ser de sonido, que de imagen. Desde luego lo que estoy diciendo es una exageración, pero no es una gran exageración [...] La narrativa de los sonidos le provoca más detonaciones que la narrativa de la imagen. Pocos directores, si no es que el único con el que yo he trabajado, tienen eso. Hablo del total de la película. Hay directores que sí piden una narrativa sonora con cosas muy específicas [...] cómo quieren que suene un tren, o un personaje en una escena. Pero Alejandro tiene esta detonación sonora en todo el filme (Alemán, 2015).

Así, es claro que existe un interés de Alejandro González Iñárritu por el sonido, su potencial creativo y su expresividad, que ha logrado entender y trabajar a lo largo de sus proyectos, tanto en radio como en televisión y cine. Para este análisis, lo relevante es el 'currículum sonoro' con el que cuenta Alejandro González Iñárritu, y que ayuda a establecer la propuesta sonora de Babel como objeto de estudio, donde se mezcla el trabajo y la sensibilidad de dos creativos mexicanos en una historia que, en su trama y en su producción, relaciona aspectos de la comunicación sonora.

\section{Lo que se dice sobre Babel}

Como primer acercamiento a la propuesta sonora que Iñárritu y Hernández presentan en Babel, se pueden explorar los textos que se han realizado alrededor de esta. Al revisar algunas críticas y reseñas sobre la película, es claro que el tema que más se comenta en dichos textos es la dificultad de comunicación entre los personajes. Esto puede ser derivado de la asociación inmediata hecha de la película con el mito bíblico. En cuanto a la propuesta sonora, los pocos comentarios encontrados sobre este aspecto están centralizados en la música compuesta por el argentino Gustavo Santaolalla y algunos ritmos que atraviesan la cinta, como los de Celso Piña y su Cumbia sobre el río, Chavela Vargas interpretando Tú me acostumbraste o la música electrónica utilizada en el bar en Tokio. Entre las reseñas resalta la de Glenn Kenny (2010), en un texto para la Film Society of Lincoln Center, donde da cuenta de lo complejo del proyecto narrativo de Iñárritu en cuanto a tejer el relato y atravesar todos los tópicos que utiliza. "Babel is a film of ambitious scale. While each of its individual stories is told in a relatively intimate style, framing characters almost uncomfortably tightly with handheld camerawork, the film's arc of interconnected narratives touching on such current topics 


\section{DISERTACIONES}

ESTUDIOS

El papel del sonido en la comunicación: contribución, funciones y efectos

ISSN: $1856-9536$

Doi: http://dx.doi.org/10.12804/revistas.urosario.edu.co/disertaciones/a.6419

Volumen 12, Número 2 / Julio-diciembre 2019

Versión PDF para imprimir desde

http://revistas.urosario.edu.co/index.php/disertaciones

as terrorism, immigration, the remnants of American and European colonialism and imperialism -ranges across the entire world-" (p. 48). ${ }^{1}$

Algunos críticos continúan manejando el término de banda sonora para referirse exclusivamente a la música, como en el caso de Babel: narrativa de la incomunicación (Garcés, 2013) donde afirman que "la banda sonora es uno de los elementos que cobra más importancia en el desarrollo del film, convirtiéndose en un actor más en escena. Es multicultural como los personajes, en ella te puedes encontrar un bolero, una cumbia, sonido de banda, así como pop japonés" (p. 23).

En muchas películas, al igual que en Babel, los ritmos musicales también pueden ser caracterizados con un mismo personaje que atraviesa las escenas, sin embargo, dicho personaje estaría construido con una base que deja fuera otras expresiones sonoras. No obstante, y como ya se explicó, la música hace parte de los elementos que edifican la banda sonora, y en esta reseña se pueden encontrar elementos que van más allá de los meros ritmos:

[...] la realidad es que para construir la banda sonora se utilizó el mismo instrumento (conexión) en cada una de las tramas: un oud (instrumento de cuerda). Este instrumento carece de trastes, por lo que permite falsear perfectamente el sonido de otros instrumentos. En Asia suena un koto japonés, en América, como una guitarra española y en África, como un barbat (antigua guitarra de origen persa). Esta técnica sonora funciona en sintonía con el corpus de la película, y acaba conectando todos los personajes y todos los lugares de una manera complementaria a la historia y las imágenes (Fernández Garcés, 2013, p. 24).

Los instrumentos musicales son utilizados para conectar personajes que traspasan los tiempos, los espacios y la cultura de los protagonistas. En este sentido, y pensando en la relación entre sonido y cultura, en el artículo "Babel: cine y comunicación en un mundo globalizado" (2012), Carmen Pereira Domínguez, Jordi Solé Blanch y Luis Fernando Valero Iglesias hablan de una "amalgama" de sonidos preeminentes y definitorios de la variedad basada en la tradición y en sus diversas evoluciones, es decir, el sonido se adapta, también, a la multilateralidad. Lo intercultural se acepta como una consecuencia amplia de nuestras innatas distinciones. Es decir, la película plantea un reconocimiento de la otredad a partir de lo sonoro.

Puede percibirse que estos textos dan cierta relevancia al sonido como conector y aglutinador de contextos, aunque, como ya se comentó, se limitan a lo meramente musical o instrumental. Sin embargo, algunos autores reconocen que, gracias al personaje de Chieko, la adolescente nipona y sorda, la película explora las posibilidades narrativas del silencio, de una manera acertada y propositiva. En "Quisiera hablar de la película Babel de Alejandro González Iñárritu" (2007), Arroyo afirma que la película "capta y transmite emociones sin palabras; las tomas en la discoteca japonesa y la bien lograda ambientación sin sonido invitan al espectador a la reflexión sobre los pensamientos de la joven japonesa", planteamiento que se sintoniza con lo que otros críticos han comentado acerca de la mixtura sonora y musical que también maneja la película, ahora complejizada con el uso del silencio.

1 Babel es una película enormemente ambiciosa. Mientras que cada una de las historia es contada con una factura de intimidad, y la cámara móvil enmarca personajes de manera angosta e incómoda, el arco de la película de estas narrativas conectadas trabaja temas como terrorismo, migración, remanentes del colonialismo y del imperialismo americano y europeo, las multiplicidades a lo largo y ancho del globo. T. del A. 


\section{DISERTACIONES}

ESTUDIOS

El papel del sonido en la comunicación: contribución, funciones y efectos

ISSN: $1856-9536$

Doi: http://dx.doi.org/10.12804/revistas.urosario.edu.co/disertaciones/a.6419

Volumen 12, Número 2 / Julio-diciembre 2019

Versión PDF para imprimir desde

http://revistas.urosario.edu.co/index.php/disertaciones

Un análisis de Pellicer (2010) de la misma secuencia nocturna en el bar de Tokio comenta que "Chieko [la chica japonesa] vive la soledad de la adolescencia agravada por el aislamiento y la inseguridad que provoca la dificultad para entender lo que dicen los oyentes y la aún mayor dificultad de los oyentes de entender lo que dicen los sordos" (p. 119).

En este primer acercamiento a lo que se dice de Babel son relevantes las críticas o reseñas a la propuesta sonora, y como un eco de lo que sucede en la literatura sobre lo visual y lo sonoro, este último no es asunto que, estadísticamente, parezca resultar de mucho interés, ya que lo poco escrito sobre la banda sonora, como ya se mencionó, solo se limita a la propuesta musical del film.

\section{La metodología de Chion y la estructura de Babel}

Antes de iniciar el arduo proceso de análisis e inmersión en una obra audiovisual, Chion propone ser rigurosos con la terminología que se utiliza en toda investigación: "iPor qué decir un sonido cuando puede decirse un chisporroteo, un gruñido o un trémolo? El empleo de estas palabras más rigurosas y específicas permite confrontar las percepciones unas con otras y avanzar en su definición y su localización. El simple hecho de tener que buscar en la lengua aquello de lo que ya se dispone crea una actitud de espíritu que incita a interesarse más de cerca por los sonidos" (1993, p. 173).

Por ello, no debe sorprender que en los hallazgos y el análisis de este texto se destaquen algunos conceptos o términos nuevos, con el propósito de relacionarlos con la propuesta sonora de Babel, dado que, de algún modo, estos logran aportar significados y sentidos a la teoría del sonido.

Para un análisis completo de la banda sonora inherente a la película Babel, se utilizó la metodología de Chion que aparece en su libro Audiovisión, donde plantea ejercicios puntuales y ejemplificados, en algunos casos, para analizar el vínculo entre sonido e imagen, con otros aspectos inherentes al audiovisual. Las cinco herramientas se pueden definir de la siguiente forma.

El método de los ocultadores. Consiste en revisar, en varias ocasiones, una secuencia determinada, algunas veces, con sonido e imagen simultáneamente, otras veces, quitando la imagen y, otras, cortando el sonido. Según él, así se tiene la posibilidad de oír el sonido tal cómo es, y no como lo transforma la imagen; y ver la imagen cómo es, y no cómo el sonido la recrea. Para esto, dice Chion, también es necesario entrenarse simplemente en oír y en ver sin más prejuicios, sin proyectarse las propias percepciones con lo que sabemos de antemano.

Búsqueda de dominancias. Se trata de la realización de una taxonomía de la naturaleza de los diferentes elementos sonoros que intervienen en una escena: ¿hay palabras? ¿Música? ¿Ruidos? ¿Cuál es dominante y se destaca? ¿En qué lugar? Así, se caracteriza el aspecto general del sonido y en especial su consistencia. Él define consistencia de la banda sonora a la manera en que los diferentes elementos sonoros (ambientes, diálogos, efectos y música) están más o menos incluidos en un mismo flujo, si tienen una misma textura o, por el contrario, se oyen claramente por separado.

Localización de los puntos de sincronización importantes. Con esta herramienta, se localizan los eventuales puntos de sincronización destacados, provistos de sentido y efecto; vale decir, las conexiones más relevantes entre los sonidos y los demás elementos que forman esas secuencias. 


\section{DISERTACIONES}

ESTUDIOS

El papel del sonido en la comunicación: contribución, funciones y efectos

ISSN: 1856-9536

Doi: http://dx.doi.org/10.12804/revistas.urosario.edu.co/disertaciones/a.6419

Volumen 12, Número 2 / Julio-diciembre 2019

Versión PDF para imprimir desde

http://revistas.urosario.edu.co/index.php/disertaciones

Comparación. Muchas veces resulta interesante comparar el sonido y la imagen acerca de una misma cuestión de representación, en sus modos respectivos de situarse en relación con un mismo criterio, que puede aplicarse tanto a uno como a la otra. Por ejemplo, en el plano de la velocidad: el sonido y la imagen pueden tener velocidades contrastadas, y esta diferencia crea una sutil complementariedad de ritmo. Vale decir, se trata de cambiar la banda sonora de un fragmento por otra totalmente distinta, y a partir de eso, encontrar nuevas relaciones y sentidos.

Matrimonio a la fuerza. Lo que propone el autor con esta herramienta es tomar una secuencia de una película, separar la imagen del sonido y unir la banda visual con una selección de sonidos de acompañamiento muy contrastados, pertenecientes a géneros diversos.

Estas son las herramientas metodológicas que se proponen en Audiovisión; ahora bien, a partir del guion de Babel (encontrado en la web), se realizó un análisis estructural de la película y se identificaron cuatros líneas narrativas distintas que se repiten de manera cíclica a lo largo de la cinta. Estas líneas o historias se pueden establecer a partir de uno o dos personajes principales, en el siguiente orden:

Yussef. La primera línea argumentativa corresponde a una familia humilde en Marruecos, donde el personaje principal es Yussef, el hijo de unos 10 años de edad, que es quien detona el disparo que desencadena la tragedia principal de la película, cuya acción atraviesa todos los espacios de la narración. A partir del tiro, la familia de Yussef entra en dificultades, pues el padre decide huir de su casa con sus dos hijos varones para no ser capturados, pero todo culmina con la muerte de uno de los miembros de la familia en manos de la Policía gracias a una información errada y a la falta de comunicación entre la propia familia, los vecinos y la Policía.

Amelia. La segunda línea corresponde a la nana mexicana Amelia y todo su contexto fronterizo entre México y Estados Unidos. Su hijo se casa cerca de Tijuana, y al enterarse de que los padres de los niños americanos (Mike y Debbie) que cuida no regresarán pronto a Estados Unidos, decide llevarlos consigo a la fiesta, generando un interesante contraste cultural y sonoro entre los dos países. Sin embargo, al regresar a casa luego de disfrutar de su melódica fiesta, el cruce en la frontera se sale de control y deriva en una cadena de malas decisiones, con un desenlace desesperanzador para ella.

Richard y Susan. La pareja estadounidense de Richard y Susan, interpretados por Brad Pitt y Cate Blanchett, son los principales protagonistas de esta línea narrativa, y son quienes más padecen el problema de incomunicación, pues, aparte de no hablarse entre ellos, por una discusión de pareja, se enfrentan a múltiples problemas para lograr dirigirse a los demás en busca de asistencia médica, debido a las diferencias idiomáticas y culturales. Se encuentran de vacaciones, no están familiarizados con el idioma árabe que predomina en la región y el guía traductor con el que cuentan no siempre comunica la información correcta.

Chieko. La última línea narrativa corresponde a la adolescente sordomuda Chieko junto a su padre en Tokio. Ella es una joven con dificultades de comunicación tanto con su padre como con otros jóvenes, a esta situación se le suma la reciente muerte de su madre y la exploración de la vida sexual que comienza a experimentar. A diferencia de la incomunicación de Richard y Susan que están de excursión en un contexto ajeno, el problema de Chieko es más cotidiano y prolongado por su condición de sorda, lo que hace que su personaje en la película este tratado de una manera sonora particularmente distinta que el resto de las historias.

Estas cuatros líneas se presentan desde el comienzo de la película y se vuelven a repetir, en el mismo orden, en seis ocasiones, esto determina la estructura interna de toda la película (ver figura 2), es decir, Babel se despliega en forma encadenada mostrando seis momentos de cada uno de los cuatro relatos. Esta configuración permite 


\section{DISERTACIONES}

ESTUDIOS

El papel del sonido en la comunicación: contribución, funciones y efectos

ISSN: 1856-9536

Doi: http://dx.doi.org/10.12804/revistas.urosario.edu.co/disertaciones/a.6419

Volumen 12, Número 2 / Julio-diciembre 2019

Versión PDF para imprimir desde

http://revistas.urosario.edu.co/index.php/disertaciones

que haya una conexión entre una secuencia y la siguiente de manera única y constante, en otras palabras, existe un ritmo narrativo marcado por cada fragmento de las cuatro historias, que genera una especie de métrica entre las líneas narrativas.

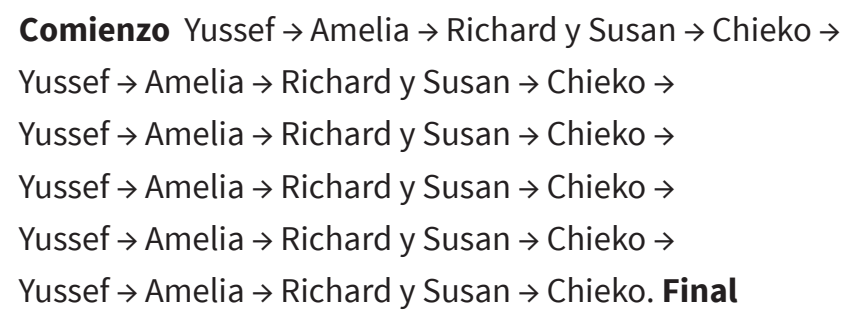

Figura 2. Línea argumental de Babel

Al contar las historias escalonadamente y al dosificar la información, tanto de acción como de lugar, tiempo y personajes, se potencializa el efecto narrativo cinematográfico del que habla Branigan (1992) cuando conceptualiza que "[...] light and sound create two fundamental systems of space, time, and causal interaction: on a screen and within a story world. One of the task of narrative is to reconocile these systems"2 (p. 65). En la pantalla, los elementos narrativos de Babel están muy bien comunicados y relacionados entre sí en función de su premisa: la incomunicación. Y aunque esta problemática está planteada en el guion, también está inmersa en los demás elementos que conforman la película. En ese sentido, la selección de los actores corresponde a la fisionomía de cada espacio geográfico; la fotografía y los encuadres se establecen desde la situación espacial y específica de cada una de las líneas narrativas, así como la propuesta de arte. Y, finalmente, el montaje pone a dialogar, en tiempo y espacio, a los diferentes personajes de la película.

Para develar las estrategias y herramientas sonoras utilizadas en cada secuencia y en la estructura total de la película, teniendo en cuenta su relación con los demás componentes del discurso narrativo, se revisaron cada una de las 201 escenas del guion, intercalando una herramienta de la metodología de Audiovisión con otra: pero no todas las secuencias fueron revisadas con las cinco metodologías, sino que, por razones temporales y de producción, solo algunas de ellas. De hecho, matrimonio a la fuerza fue el procedimiento menos utilizado en el análisis, pues, por su naturaleza, requiere mayores recursos de tiempo y de realización.

Toda la información recogida con este método se sistematizó de manera detallada en tablas, determinadas por la secuencia analizada y su correspondiente tiempo, reuniendo los elementos hallados con cada una de las herramientas metodológicas. Dichos datos se encuentran completos en numerosas cuartillas, y fueron el punto de partida para examinar y reflexionar sobre los hallazgos de la propuesta sonora de la película.

2 La luz y el sonido crean los dos sistemas fundamentales de tiempo y espacio, y su interacción causal: sobre la pantalla y como un relato sucesivo una de las obligaciones de la narrativa es conciliar esos sistemas. T del A. 


\section{DISERTACIONES}

ESTUDIOS

\section{Los hallazgos}

Aplicados los métodos de análisis y realizada la disección de los objetos sonoros en cada una de las 24 secuencias en las que se estructura Babel, se revelaron muchos aspectos relacionados con la banda sonora y su aportación a la película. Para poder llevar a cabo un análisis apropiado, se hizo una selección de los hallazgos más reiterativos, evidentes o que pudiesen ser tomados como modelos de estrategias sonoras en una producción audiovisual. A continuación, se presentan los más destacados, agrupados por las conexiones que pudieran tener entre sí.

En la primera secuencia, "The Rifle" en el guion, el arma se constituye como un objeto mágico como lo define Italo Calvino (1989, p. 119); en este sentido, el sonido refuerza la importancia narrativa del elemento dentro de la trama. El disparo que realiza Yussef a un autobús en movimiento desde la colina (ver figura 3) es fundamental para el desarrollo de la historia, pues detona la tragedia que atraviesa, de manera directa e indirecta, a todos los personajes. En esa secuencia, cuando Yussef toma el rifle para hacer una prueba de distancia, antes de que el tiro suene, se genera un precedente a su existencia, a su 'deber ser', es decir, se propaga un silencio breve, donde los ambientes son percibidos como muy tenues, permitiendo definir claramente el nacimiento del efecto sonoro del disparo.

Barenboim (2008) describe mejor este fenómeno: "El sonido que interrumpe el silencio representa una alteración de una situación existente, mientras que si surge de él es una alteración gradual de la situación existente. En términos filosóficos, podría decirse que es la diferencia entre ser y devenir" (p. 19). Tal vez por ello, en la propuesta sonora de esta secuencia se hace una antesala de silencio, se suprimen los sonidos y se crea una alfombra roja de mutismo ante el efecto sonoro, para que el disparo resuene como un objeto sonoro-mágico.

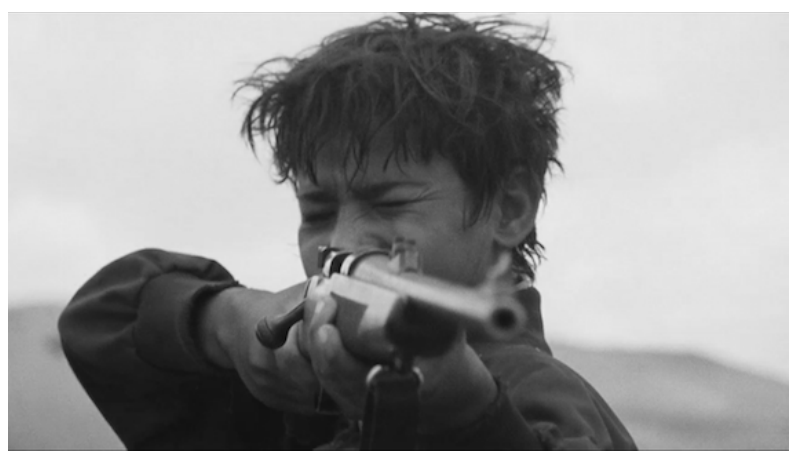

Figura 3. "The Rifle"

Por una rivalidad con su hermano Ahmed, Yussef hace un disparo a un bus que pasa a casi tres kilómetros de distancia. Pretende comprobar el alcance del rifle que acaba de comprar su padre. La presencia sonora refuerza el poder y la trascendencia del balazo en la trama de Babel.

El sonido final de esta secuencia coincide con el sonido inicial de la siguiente, los hermanos, tras darse cuenta de que la bala ha pegado en el bus, corren en la colina y sus pisadas sobre las piedras se mezclan con los pasos de unos niños que corren en una casa (ver figura 4), en circunstancias muy diferentes. En este nuevo espacio, el contexto sonoro es distinto al anterior, al igual que la temporalidad, la locación, el país y los personajes. 


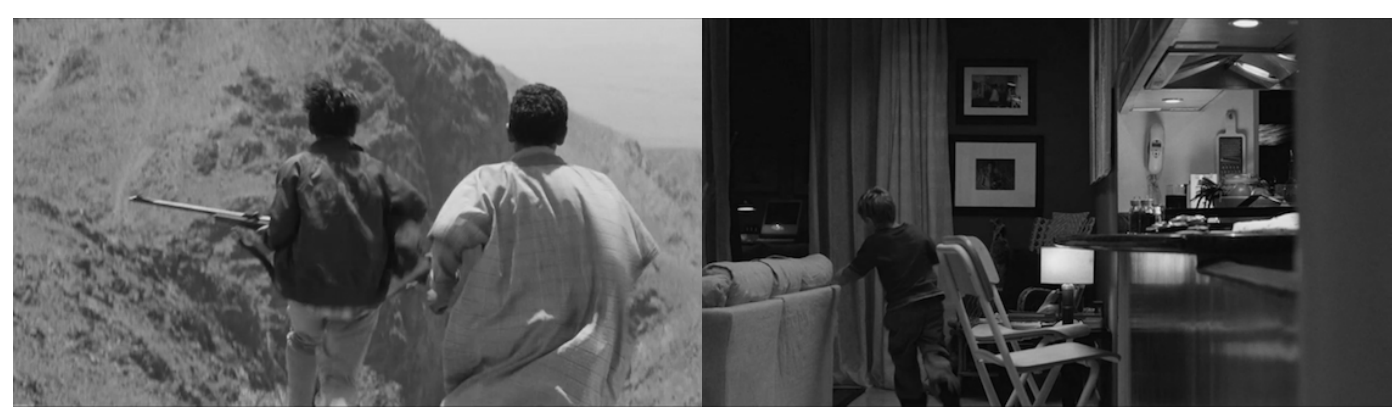

Figura 4. Sonido y edición

Yussef y su hermano corren después de detonar el disparo y los sonidos de sus pisadas se mezclan con los zapatos de Mike en otro lugar y en otra temporalidad. Al transcurrir la película se sabrá que la escena con Mike, en el tiempo-narrativo de la historia, ocurre después del disparo en Marruecos. Se puede afirmar que el sonido es usado para realizar diálogos espacio-temporales.

Otro punto donde se puede encontrar también este uso del sonido en el montaje de la película es en la secuencia 11 ("Local Medicine"), pues en la edición se aprovechan los cortes de los planos para tener efectos distintos de los diálogos. Es decir, las voces de los personajes se introducen de un plano a otro, atravesando los espacios; además, se escucha dentro de una casa lo que sonoramente sucede afuera: en esa escena, se identificó que las voces cambian de acuerdo con el corte y el tamaño del plano.

Por otro lado, en la secuencia 2, "Search for a Baby Sister", se introduce por primera vez la música en la película y nuevamente el sonido es usado para conectar escenas. Además, en el interior de una casa, se comienza a escuchar una música (extradiegética), pues no se sabe de dónde proviene, en el siguiente plano, frente a esa casa, se estaciona un auto (ver figura 5), que resulta ser la fuente de dicha música (diegética): esta estrategia sonora redunda en que la música inicial de naturaleza extradiegética se transforma en música diegética en la misma escena.

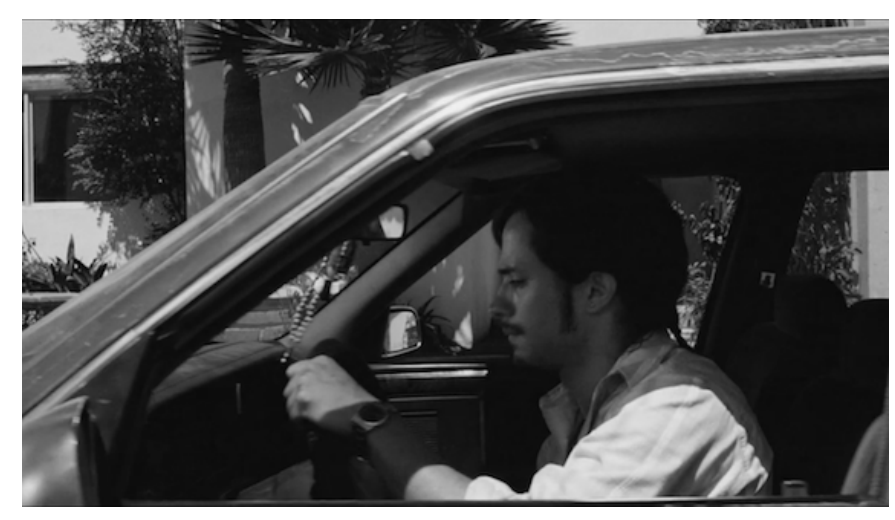

Figura 5. Música extradiegética se transforma a diegética 
Desde el interior de la casa se escucha música de banda del norte de México (extradiegética), luego vemos a Santiago (Gael García Bernal) llegar en un carro, para recoger a su tía Amelia y llevarla a la boda en México. Al apagar el motor del auto, se deja de escuchar la música, lo que la confirma como en sonido diegético.

En la secuencia 6 ("Guilt Sick"), se presenta un contraste constante entre el adentro y el afuera, es decir, se muestra una oposición entre los sonidos interiores de una casa y los exteriores de su ambiente. Y en este continuo diálogo, un efecto de chirrido de puerta (ver figura 6) se transforma en un estribillo de tensión para los personajes que allí se encuentran.
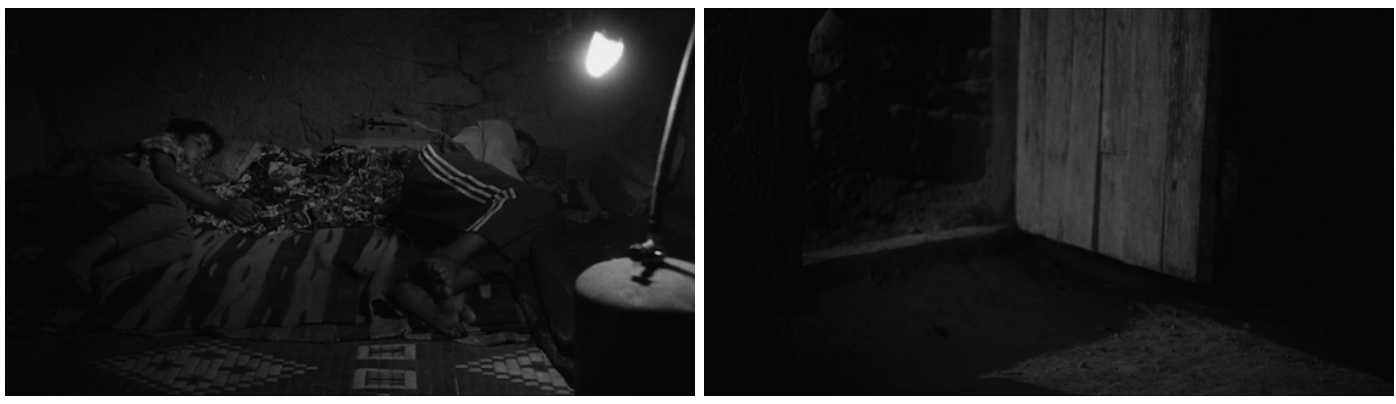

Figura 6. El sonido como tensión

Yussef y Ahmed están recostados en su cama, minutos antes su padre les ha contado que han asesinado a una americana en un autobús. Ellos quedan preocupados y silenciosos, escuchan la mezcla de los sonidos de adentro y afuera de su casa, luego, el efecto de puerta rechinando crea una enorme tensión y un contraste entre el interior y el exterior.

El recurso de enlazar secuencias con otras a través del sonido es utilizado nuevamente al final de la secuencia de Amelia (Ilamada "Crossing The Border"), pero no solo cruzando en sonido de una a otra, sino de una manera más narrativa, es decir, en la primera escena se presentan niños corriendo en una finca, intentando atrapar gallinas, con presencia de sonidos de aleteos, pisadas, risas y gritos de juego, que se transmutan, en corte directo, a los sonidos de un grupo de personas, en un bus, alrededor de Susan (Cate Blanchett) con gritos, cuerpos rozándose y barullo en varios idiomas. En este caso, las dos escenas de grupo poseen similitudes sonoras, las texturas se asemejan y hasta parece que tuvieran una misma personalidad. Este tipo de propuesta genera una fluidez en la continuidad sonora y narrativa, por demás interesante, que podría ser utilizada en otros proyectos audiovisuales.

En la secuencia denominada "In Need of a Doctor" (ver figura 7), aparecen presencias sonoras totalmente nuevas, que no se habían encontrado hasta ahora en la película. En medio de la música, emerge un sonido con frecuencias graves, de continuidad sinuosa y con una intensidad que va aumentando constantemente. Al parecer, este sonido es de naturaleza sintética, es decir, no corresponde a sonidos realizados por instrumentos musicales, sino por sintetizadores o procesadores digitales. Este sonido es cortado por el diálogo telefónico de Richard (Brad Pitt) con su asistente. 


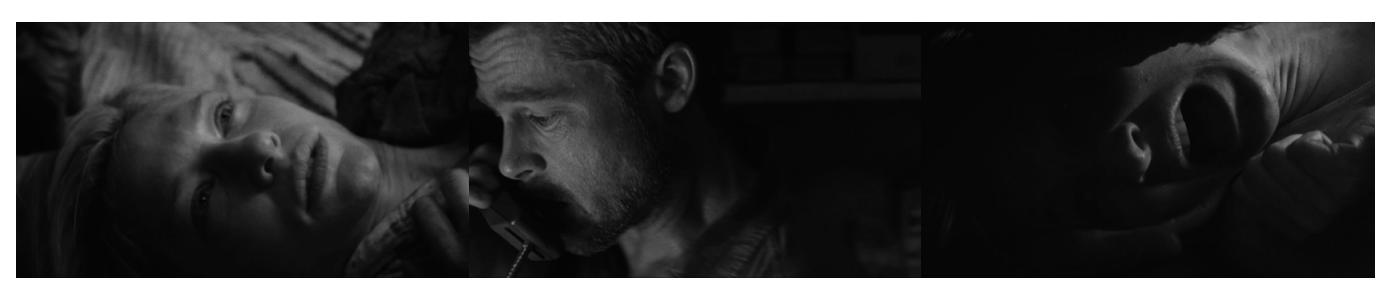

Figura 7. "In Need of a Doctor"

La herida de bala de Susan es suturada y sus gritos se ahogan en el silencio de la escena siguiente.

En otras escenas también se identificaron distintas presencias sonoras que no pudieron ser clasificadas dentro de las categorías del sonido en el cine (ambientes, diálogos, efectos y música). Una de las más evidentes se encontró, al inicio de la secuencia "Tokyo Night" (ver figura 8), donde Chieko está, al parecer, en un estado alterado de conciencia después de tomar una píldora que le fue ofrecida por el primo de su amiga. Todos los sonidos propios de la escena son eliminados por completo y reemplazados por un flujo de sonido desconocido, que nuevamente no corresponde a una composición musical, sino que se asemeja más a un torrente de distintas entidades sonoras de naturaleza sintética, un caudal de objetos sonoros electroacústicos de frecuencias variables, con tonalidades y texturas diversas, que finalmente, para efectos de esta investigación, fueron denominados 'entes sonoros'.

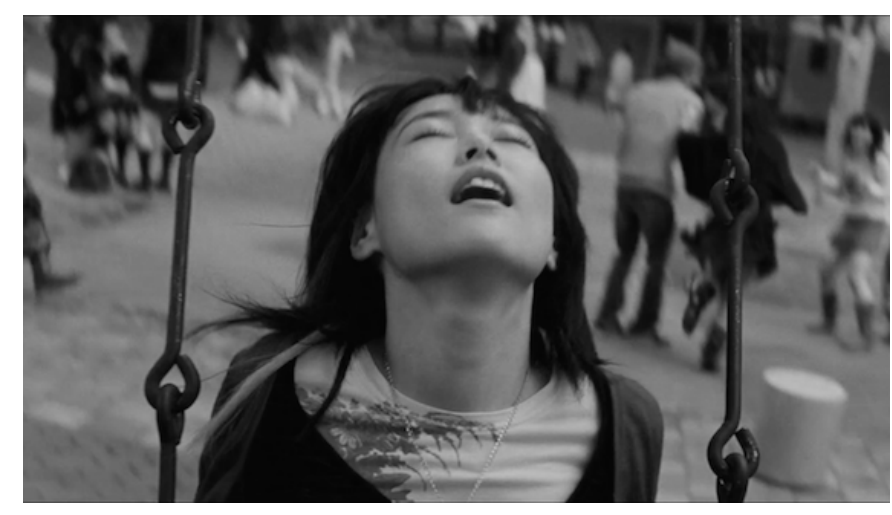

Figura 8. Chieko en estado alterado

Chieko coquetea con Haruki, un joven japonés que le ofrece una pastilla que ella acepta tomar de inmediato; a continuación, se presenta una secuencia de Chieko jugando con sus amigos y en estado de éxtasis, con una presencia sonora poco común.

En varias partes de la película se encontraron estas presencias o entes sonoros, la secuencia 15 ("No Transportation") comienza precisamente con uno de estos entes y termina con otro distinto, lo mismo ocurre en la secuencia 17 ("Surrender"), donde se distingue un ente sonoro que desaparece para darle entrada al ambiente que corresponde a la escena próxima. Del mismo modo, en "Lost in the Desert" (secuencia 18) se detectó un flujo sonoro al comienzo, y que apenas se distingue de la música. 


\section{DISERTACIONES}

ESTUDIOS

El papel del sonido en la comunicación: contribución, funciones y efectos

ISSN: 1856-9536

Doi: http://dx.doi.org/10.12804/revistas.urosario.edu.co/disertaciones/a.6419

Volumen 12, Número 2/ Julio-diciembre 2019

Versión PDF para imprimir desde

http://revistas.urosario.edu.co/index.php/disertaciones

Por otra parte, al final de la secuencia "In Need of a Doctor" (ver figura 7), Susan se lamenta de manera desgarradora, pues le están realizando suturas en su herida de bala sin estar anestesiada. Sus gritos contrastan con el comienzo de la escena posterior, que es totalmente silente y corresponde a la secuencia 8 ("Police Visit"). Esta última secuencia, al parecer, pretende emular la experiencia de Chieko en un consultorio odontológico, pues en una perspectiva subjetiva de ella (que espera ser atendida por el doctor) son eliminados los ambientes, los efectos sonoros y los diálogos. Pero se puede ver que la gente está hablando, aunque no se escuche lo que se dicen. De hecho, esta escena es la primera, sin audio, en toda la película, y el silencio será utilizado como estrategia en otras escenas de Chieko.

El final de la trama de Babel se desencadena a partir de la secuencia 21 ("Deported") y de aquí hasta los créditos finales es evidente el privilegio dado a la música. "Leaving the Village", que corresponde a la secuencia 22 (ver figura 9), inicia con una pieza musical a base de instrumentos de cuerdas de Gustavo Santaolalla. En esta propuesta musical se puede identificar con claridad los narrative cueing que conceptualiza Claudia Gorbam en su texto Unheard Melodies: Narrative Film Music: "Narrative cueing: - referential/narrative: music gives referential and narrative cues, e. g., indicating point of view, supplying formal demarcations, and establishing setting and characters. Connotative music 'interprets' and 'illustrates' narrative events”3 (1987, p. 79). Esta melodía es mezclada con los efectos sonoros de un helicóptero y algunas voces, y, después de una fuerte presencia melódica, se consigue un breve silencio donde se logran escuchar dos conversaciones que aportan información fundamental para la resolución del argumento: la recuperación de Susan y el ordenamiento cronológico de lo sucedido en la frontera, y todo esto se consigue gracias al sonido y, en este caso, con aportaciones musicales.

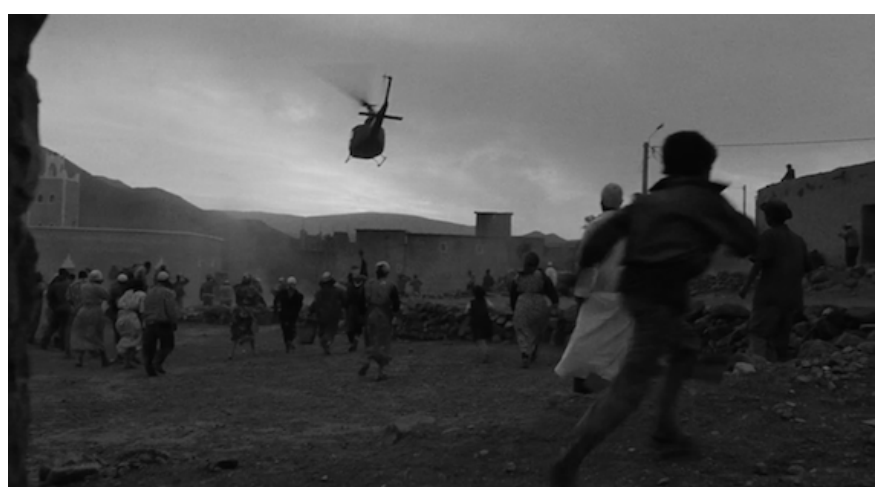

Figura 9. Constante música

3 Indicadores narrativo: - referencial/narrativo: la música proporciona claves de referencia y narrativas, por ejemplo, indicando el punto de vista, proporcionando demarcaciones formales y estableciendo escenarios y personajes. La música connotativa 'interpreta' e 'ilustra' eventos narrativos. T. del A. 


\section{DISERTACIONES}

ESTUDIOS

El papel del sonido en la comunicación: contribución, funciones y efectos

ISSN: $1856-9536$

Doi: http://dx.doi.org/10.12804/revistas.urosario.edu.co/disertaciones/a.6419

Volumen 12, Número 2 / Julio-diciembre 2019

Versión PDF para imprimir desde

http://revistas.urosario.edu.co/index.php/disertaciones

Durante casi toda la secuencia hay presencia de la música de Santaolalla, intercalada con algunos diálogos.

En resumen, de las contribuciones sonoras derivadas de la metodología de Chion, se reconocen algunos procedimientos que fueron utilizados reiteradamente en distintos puntos de la película, como el caso del sonido en sintonía con el montaje o la edición, observable en los cortes entre planos y la continuidad en casi todas las secuencias. Además, sobresale el contraste permanente entre los distintos paisajes sonoros en los que se desarrolla la trama, pues en la construcción de los ambientes se revelan sonoridades constantes sin muchas variaciones morfológicas internas, pero que sirven para desentonar con otros paisajes. El uso del silencio también es un punto notable de la propuesta sonora, claramente centralizado en las secuencias de Chieko, enunciando una determinada comunicación con el mundo y con ella misma. Así, es loable el manejo narrativo del sonido en un diálogo constante entre los universos diegéticos y extradiegéticos, pues este contraste, muchas veces difícil de percibir, ayuda a la construcción de un relato de una alta expresividad.

En último término, vale la pena agregar que uno de los hallazgos más relevantes e interesantes dado con esta metodología es la presencia de algunos objetos que atraviesan el flujo sonoro de la película, pero que no encajan en ninguna categoría establecida inicialmente, y los que se denominaron entes sonoros.

\section{Los entes sonoros}

En la taxonomía de una banda sonora, se pueden distinguir cuatro categorías para los elementos ontológicos del sonido en una película: ambientes, diálogos, efectos y música. Sin embargo, en la propuesta sonora de Babel se detectaron ciertas sonoridades que no se ajustaron en las distintas categorías establecidas, por ello surgió la necesidad de nominar dichas presencias con el concepto de entes sonoros.

Estos entes pueden definirse como aquellos flujos sonoros dentro de una propuesta cinematográfica que no tienen un uso aparente o un sentido concreto dentro de la historia y que se distinguen de los ambientes, efectos, diálogos y música. Claro está que, conceptualmente, un ente sonoro puede ser confundido con un objeto sonoro, sin embargo, este último es considerado como la unidad mínima del sonido, lo que equivale a la gota de un flujo, mientras que el ente es un caudal, un movimiento de sonoridades más elaborado y complejo. También habría que delimitar la diferencia entre ente sonoro y música, ya que acústicamente podrían tener rasgos similares, no obstante, divergen en cualidades como melodía, armonía y ritmo, que son fundamentales en la música, atributos de los que carecen los entes sonoros.

Dentro de las características que sí son reconocibles en los entes se pueden determinar las siguientes:

- Fuente. El origen sonoro de los entes es desconocido, su naturaleza pertenece a la narración extradiegética.

- Sonoridad o texturas sonoras. Determinadas por los materiales que constituyen su naturaleza, es decir, según el ADN sonoro del que están compuestos. En el caso de los entes, se utiliza una mezcla de diversos materiales (sonoridades lisas, algunos objetos rugosos, crepitantes, duros y otras formas más), pero siempre se trata de un flujo sonoro peculiar, vale decir, los entes sonoros cuentan con una nutrida mixtura de morfologías sonoras.

- Duración. A diferencia de los efectos que tienen una vida audible bastante corta, las oscilaciones de los entes sonoros resultan de mayor permanencia en la banda sonora; son presencias que, en algunos casos, atraviesan varias escenas, rompen el tiempo y el espacio narrativos. 


\section{DISERTACIONES}

ESTUDIOS

El papel del sonido en la comunicación: contribución, funciones y efectos

ISSN: $1856-9536$

Doi: http://dx.doi.org/10.12804/revistas.urosario.edu.co/disertaciones/a.6419

Volumen 12, Número 2 / Julio-diciembre 2019

Versión PDF para imprimir desde

http://revistas.urosario.edu.co/index.php/disertaciones

- Expresividad. No se cuenta con una fuente sonora que determine la naturaleza de los entes sonoros, y, por lo tanto, no es posible explicitar la narrativa o marcar un estado de emoción específico y de más fácil lectura, como sí sucede en algunos casos con la música o los efectos sonoros (que permiten apoyar un estado de ánimo o una situación ya enmarcada por la relación entre imagen y sonido). En consecuencia, la ausencia de utilidad o la ausencia de funcionalidad de los entes sonoros puede ser precisamente su cualidad más importante, pues, lejos de convertirse en un acompañamiento de cualquier elemento de la película, estos entes expanden los confines actuales que tiene la banda sonora cinematográfica.

Entonces bien, ahora queda sumar los entes sonoros a las demás estrategias y procedimientos formales encontrados en Babel (como el uso del sonido en el montaje, el alto contraste entre sonoridades antagónicas o la participación del silencio en algunas secuencias, el diálogo entre los universos diegéticos y extradiegéticos), para hilvanar conceptos o deducciones que ayudan a enriquecer la forma en que el sonido es utilizado en un discurso narrativo, especialmente el cinematográfico, de manera propositiva y expresiva.

\section{Resonancias finales: conclusiones}

Luego de los análisis realizados sobre la propuesta de sonido de la película Babel y los hallazgos derivados de dicha inmersión, se puede afirmar que esta banda sonora es un complejo flujo que se relaciona y dialoga constantemente con los diferentes elementos de la película: guion, fotografía, actuación y posproducción, diseñado de una manera consciente y expresiva por el equipo de realización.

En primera medida, en el montaje de Babel, la banda sonora fue aprovechada como elemento de corte o de transición entre un universo narrativo y otro en reiteradas ocasiones y con diversas estrategias (corte, continuidad y contraste). Probablemente la decisión de usar el sonido como aglutinante de planos y secuencias se deba a su especial fluidez, es decir, debido a su continuo devenir, ya que en el sonido no es fácil identificar los cambios en sus materiales o matices, lo que permite distraer el sentido del oído, y así, dificultarle al oyente (en ese caso un espectador cinematográfico) identificar los cortes de la película. Esta característica no es tan rentable en el trabajo con la imagen, pues cualquier variabilidad o contraste en el plano visual es imperativamente percibido de inmediato.

Esta cualidad del sonido ha estado inadvertida para la mayoría, dado que se requirió de un estudio minucioso y de una escucha meticulosa para detectar el fenómeno. En varias secuencias de la película, como se detalló en los hallazgos, el sonido ambiente, los efectos, la música, los diálogos y los entes sonoros fueron usados en el montaje en constante diálogo con las imágenes y la trama, siempre fracturando el espacio y el tiempo en el que el sonido precedía a la secuencia siguiente.

Por otro lado, una de las particularidades de la película Babel, y que la conecta inexorablemente con el mito bíblico, es la presencia de múltiples acentos dentro de las distintas secuencias, lo que hace que exista una diversidad de idiomas pronunciados por sus personajes. Claro está que la variedad fonética que se puede encontrar en los distintos diálogos de la película abona diversos acentos al flujo sonoro y transforma morfológicamente el vocentrismo de Chion (1993), pues este afirma que el sonido en el cine favorece a la voz, destacándola entre los demás sonidos de la banda sonora. Y aunque se puede decir que, en Babel, no hay un abuso de este vocentrismo, es ineludible reconocer que, como en la mayoría de los guiones cinematográficos, en los diálogos se resuelven muchas de las acciones que desarrollan el relato, y la voz tiene un lugar privilegiado en el diseño sonoro final.

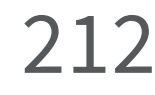




\section{DISERTACIONES}

ESTUDIOS

El papel del sonido en la comunicación: contribución, funciones y efectos

ISSN: 1856-9536

Doi: http://dx.doi.org/10.12804/revistas.urosario.edu.co/disertaciones/a.6419

Volumen 12, Número 2 / Julio-diciembre 2019

Versión PDF para imprimir desde

http://revistas.urosario.edu.co/index.php/disertaciones

En este sentido, las voces de los personajes fueron trabajadas para que transmitieran algo más allá de la información literal que emiten, por ello, los diálogos de los personajes adquieren una dimensión más compleja, como es el caso de la confesión de Yussef, pues su voz se destaca por la intencionalidad actoral y por la expresividad que emanaba del sentimiento con el que habla, aunado a las expresiones corporales, a la reacción de los otros personajes y, finalmente, al montaje. Entonces, acá, la voz es usada como una esencia de los personajes, es la cualidad que define su otredad sonora, la voz más allá de la corporalidad o, en palabras de Dolar (2007): "La voz, al ser tan efímera, transitoria, incorpórea y etérea, presenta por ese mismo motivo al cuerpo en su quintaesencia, al tesoro corporal oculto más allá de la envoltura visible, al cuerpo real, único e íntimo, y al mismo tiempo parecería presentar más que el mero cuerpo" (p. 87).

En Babel, como ya se determinó, se problematiza el tema de la comunicación, y en este sentido el sonido opera en tres direcciones: 1) la incomunicación por diferencia idiomática, incomprensión y desarraigo; 2) por omisión de las facultades auditivas; y 3) ausencia de información por decisión o falta de interés; además, el universo sonoro en el que están inmersos los personajes los distinguen de los demás. Estos aspectos dejan abierta la discusión acerca de la tragedia de la incomunicación contemporánea, que hace eco con el mito bíblico de la arrogancia de la naturaleza humana.

Otra aportación muy relevante en la construcción del relato, y ubicados en varias secuencias (como un efecto telefónico, un disparo, un efecto de motor de bus alejándose, entre otros) son los sonidos-detonantes de las acciones de los personajes. Es decir, de una manera poco usual en el cine, el sonido desencadena la historia y se convierte en una presencia clave del guion sin la cual esa parte del relato no sería coherente. Se destaca, entonces, que los objetos sonoros son aprovechados como objetos narrativos desde la construcción original del guion.

En contradicción a las potencialidades sonoras encontradas en Babel a través de los ambientes, los efectos sonoros, los diálogos, la música y los entes sonoros, la ausencia consciente de todos ellos también hace parte de la propuesta sonora del film. El uso del silencio representado no solo por el personaje sordomudo de Chieko, sino también en el tratamiento de algunos ambientes y escenas específicas en la historia de este personaje, resultaron elementos fundamentales para generar contraste y estética sonora en la narrativa. Dicho de otro modo, se identificaron algunas aportaciones por el uso del silencio cuando este se planteó más allá de la sola ausencia de sonido, y se aprovechó la expresividad que se encontrada en el devenir del sonido siguiente.

Como ya se comentó, en la secuencia inicial de la película, la presencia del primer disparo es fundamental para el desarrollo de la trama, pues, es precedente a su existencia, a su 'deber ser', y se genera a partir de un breve silencio. Tal vez por ello, en la propuesta se hace una antesala de silencio, para que el disparo resuene como premonición de lo que sucederá. El silencio puede ser usado como elemento expresivo, otra vez es Dolar quien sintetiza esto muy bien: "Entonces el arte del silencio es parte de la retórica; es un arte de cómo influir lo mejor posible en el destinatario. Ya los antiguos retóricos proponían agregar un silencio retórico a su bolsa de trucos. El silencio trabaja como el soporte eficaz que inviste las pocas elegidas por su propio peso" (p. 181).

El silencio aporta, en la narrativa, por los sonidos que le anteceden, pero, sobre todo, por aquellos que suenan y nacen después de un vacío sonoro. La película Babel ejemplifica, de una manera creativa y propositiva, las dificultades en el proceso de comunicación personal, es decir, escala la tragedia que involucra la historia bíblica de Babel a un nivel ya cotidiano. Y esto se lleva al límite en algunos de sus personajes, como el caso de Chieko, que son acentuados y particularizados por sus construcciones sonoras y el uso retórico del silencio.

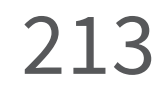




\section{DISERTACIONES}

ESTUDIOS

El papel del sonido en la comunicación: contribución, funciones y efectos

ISSN: $1856-9536$

Doi: http://dx.doi.org/10.12804/revistas.urosario.edu.co/disertaciones/a.6419

Volumen 12, Número 2 / Julio-diciembre 2019

Versión PDF para imprimir desde

http://revistas.urosario.edu.co/index.php/disertaciones

Por otra parte, la utilidad o funcionalidad específica de los llamados entes sonoros es una premisa ardua de encontrar, dada su naturaleza desconocida y polisémica, pues no se le puede atribuir un sentido único a estos sonidos. Una de las razones de esta dificultad se vincula con el posible diálogo entre los entes sonoros y su potencial generador de fantasía. Al respecto señala Dolar: "[...] la voz, los ruidos, lo oído, constituyen el núcleo de la formación de la fantasía; una fantasía es una fabulación construida alrededor de un núcleo sonoro” (p. 162). Es por esto que el poder expresivo de los entes sonoros se vincula con cada uno de los escuchas, lo que equivale a plantear que la construcción de la fantasía que se da a partir de los materiales propuestos es completada por cada uno de los espectadores, con su propia vivencia. "Los sonidos [o entes sonoros], esos intrusos que nadie invitó y que parecen cargar misteriosamente un sentido en sí mismos, independientemente de lo que se quiera expresar, excederán lo que intenten decir" (Dolar, 2007).

En definitiva, los entes sonoros aportan en la potencialización de la experiencia estética de la película, y es esta característica la que contribuye, de manera contundente, en la expresividad de la banda sonora, que al final modifica el entramado que resuena en todo Babel. La gran expresividad de los entes de Babel se afinca en la simulada inutilidad narrativa, en su aparente futilidad, que le otorga un carácter comunicativo y afectivo único y casi inaprensible. Todo esto coloca la banda sonora de Babel como ejemplo emblemático para desentramar procedimientos, herramientas y estrategias sonoras que enmarcan la 'expresividad de lo inútil' y, lo que es mejor aún, le otorgan un sentido estético al sonido en el lenguaje cinematográfico.

Otro aporte que se deriva de esta inmersión sonora puede estar determinado por el potencial del sonido como constructor de relato y discurso en un producto audiovisual, pues, si se vuelve a revisar con oídos más abiertos la producción de Iñárritu después de los hallazgos encontrados en esta investigación, se podría constatar que en el cortometraje 11'09'01 - September 11 también se encuentran algunos entes sonoros que aunados a toda la propuesta sonora hacen eco en la historia real-ficcional-bíblica, pues la tragedia concreta del desplome de las torres en Nueva York resuena con la tragedia de la incomunicación sonora en la película y, al mismo tiempo, se sincroniza con la tragedia de la fragmentación idiomática y dispersión de los hombres del mito bíblico. Todos estos relatos atravesados por flujos sonoros, textuales, reales y ficcionales, pero que al final crean sentido para potenciar una premisa: conflictos con la otredad.

Finalmente, propuestas de sonido como la de Babel permiten argumentar que en la banda sonora de una película no solo los sonidos diegéticos son funcionales; la existencia de presencias sonoras casi fantasmagóricas y acusmáticas ayudan a ampliar la expresividad sonora y dejan en el escucha la posibilidad de desafiar sus propias fantasías, como lo plantea el filósofo Mladen Dolar, para que los espectadores se transformen, así, en actores más activos en la experiencia cinematográfica.

Por todo esto, sería idóneo realizar ejercicios de sensibilización sonora, principalmente con los hacedores cinematográficos, involucrando a directores, guionistas, fotógrafos y todos aquellos relacionados con la realización, esto con el fin de que identifiquen y se apropien de estrategias que permitan nutrir el diálogo entre el sonido y el oficio que cada uno desempeña en beneficio de la historia por contar.

En definitiva, aunque estemos cotidianizados con numerosos paisajes y objetos sonoros, aún estamos lejos de tener una sensibilidad-reflexiva sobre nuestro entorno sonante y un reconocimiento a la otredad, por lo que se hace urgente una educación auditiva en todos los niveles, que permita relacionarnos con nuestros universos sonoros de una manera consciente, pensante y, por qué no, creativa.

\section{4}




\section{DISERTACIONES}

\section{Referencias}

1. Alemán, C. (2 de marzo de 2015). ¿Cómo suena el entorno? Entrevista a Martín Hernández. Recuperado de http://moreliafilmfest.com/como-suena-el-entorno-entrevista-a-martin-hernandez/

2. Abounouom, A. (Productor), Arriaga, G. (escritor), \& Iñárritu, A. G. (Dirección). (2006). Babel [película]. Estados Unidos.

3. Arroyo, S. (febrero, 2007). Quisiera hablar de la película Babel de Alejandro González Iñárritu. Razón y Palabra, (55). Recuperado de http://www.razonypalabra.org.mx/cyl/2007/feb1.html

4. Barenboim, D. (2008). El sonido es vida. El poder de la música. Bogotá: Editorial Norma.

5. Bejarano, M. (2007). Música contreta. Tiempo destrozado. Bogotá: Universidad Nacional de Colombia.

6. Branigan, E. (1992). Narrative comprehension and film. Nueva York: Routledge.

7. Chion, M. (1993). La audiovisión. Introducción a un análisis conjunto de la imagen y el sonido. Barcelona: Paidós.

8. Dolar, M. (2007). Una voz y nada más. Buenos Aires: Bordes Manantial.

9. Gorbam, C. (1987). Unheard melodies. Narrative film music. Bloomington: Indiana University Press.

10. Hernández, M. (27 de febrero de 2015). Conversando con Cristina Pacheco-Martín Hernández. Ciudad de México.

11. Azcarraga, E. (Productor), Iñárritu, A. G. (Escritor), \& Iñárritu, A. G. (Dirección). (2002). 11 '09"01 - September 11 [película]. Estados Unidos.

12. Iñárritu, A. G. (Escritor), \& Iñárritu, A. G. (Dirección). (2012). Naran ja [película]. Estados Unidos.

13. Jullier, L. (2007). El sonido en el cine. Barcelona: Ediciones Paidós Ibérica.

14. Kenny, G. (2010). This can't end well how we live now, or the new humanism according to Alejandro Gonzalez Iñárritu. Film Society of Lincoln Center, 46(6), 46-49.

15. Meyer, M. (1999). El técnico de sonido. Barcelona: Debate.

16. Pellicer, J. (2010). Tríptico cinematográfico. El discurso narrativo y su montaje. Estado de México: Siglo xxı.

17. Pereira Domínguez, C., Solé Blanch, J., \& Valero Iglesias, L. F. (abril, 2012). Babel: cine y comunicación en un mundo globalizado. Polis, Revista Latinoamericana, 26. Recuperado de http://polis.revues.org/119 